\title{
Ciudad en fiesta, ciudad en disputa: el caso del Parque Augusta en São Paulo
}

Playful City, Struggling City:

The Case of Parque Augusta in São Paulo

Cidade em festa, cidade em disputa:

o caso do Parque Augusta em São Paulo

\section{Cintia Marino* \\ Abilio Guerra**}

Recibido: 15 de octubre del 2019

Aprobado: 21 de abril del 2020

https://doi.org/10.12804/revistas.urosario.edu.co/territorios/a.8353

Para citar este artículo:

Marino, C., \& Guerra, A. (2021). Ciudad en fiesta, ciudad en disputa: el caso del Parque Augusta en São Paulo. Territorios, (44), 211-238. https://doi.org/10.12804/revistas.urosario.edu.co/territorios/a.8353

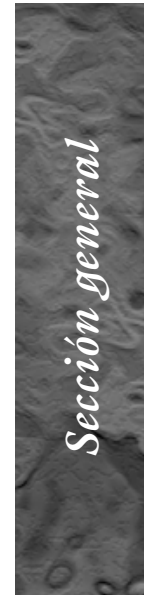

* Universidad Nove de Julho (Uninove), São Paulo, Brasil. Correo electrónico: cintiacmarino@gmail.com. ORCID: bttps://orcid.org/00000002-8756-6191.

** Universidad Presbiteriana Mackenzie São Paulo, Brasil. Correo electrónico:abilio@romanoguerra.com.br. ORCID: https://orcid.org/00000002-2207-572X. 
Palabras clave

Activismos; apropiación del espacio público; comunes urbanos; derecho a la ciudad; São Paulo.

Keywords

Activisms; urban commons; right to the city; appropriation of public space;São Paulo.

Palavras-chave

Ativismos; comuns urbanos; direito à cidade; apropriação de espaço público; São Paulo.

\section{territarias 44}

\section{RESUMEN}

El presente artículo traza un panorama sobre las dinámicas de disputa urbana y experiencias colectivas, a partir de una reflexión sobre el caso del Parque Augusta en São Paulo. Un terreno privado en el centro de la ciudad que ha logrado unificar las agendas de movimientos sociales de distintos idearios en el intento por transformarlo en un parque público. Después de varios años de apropiación espontánea por parte del vecindario, grupos activistas intensificaron las manifestaciones a partir del 2013, organizando eventos y festivales artísticos en el terreno. Así pues, utilizando los conceptos de "derecho a la ciudad" y "comunes urbanos", este análisis describe la trayectoria del caso e identifica las contradicciones generadas a lo largo del proceso. En términos metodológicos, la investigación se llevó a cabo mediante narraciones, escala espacial, recorte temporal, cuestionamientos y conceptos. Con lo cual se demuestra que la experiencia colectiva observada parece requerir un nuevo proceso para producir un espacio público democrático.

\section{Abstract}

This article aims to provide an overview of urban dispute dynamics and collective experiences, based on a reflection on the case of Parque Augusta, in São Paulo. A private plot of land in downtown São Paulo has unified the agenda of social movements with diverse ideology, in order to transform it into a public park. After several years of spontaneous appropriation by neighbours, from 2013 on activists have intensified direct actions, organizing art and culture events and activities. Using the concepts of "right to the city" and "urban commons", the case analysis describes the trajectories of the groups and identifies some contradictions generated throughout the process. In methodological terms, the investigation is conducted through narratives, spatial scale, time frame, questions and concepts. The observed collective experience seems to require a new process to produce democratic public space.

\section{RESUMO}

O artigo traça um panorama sobre dinâmicas de disputa urbana e experiências coletivas, a partir de uma reflexão sobre o caso do Parque Augusta, em São Paulo. Um terreno de propriedade privada no centro da cidade conseguiu unir as agendas de movimentos sociais de distintas ideologias com o objetivo de transformá-lo em um parque público. Depois de vários anos de apropriação por parte dos cidadãos da vizinhança, grupos ativistas intensificaram as manifestações a partir de 2013, organizando eventos e festivais artísticos no terreno. Utilizando os conceitos de "direito à cidade" e "comuns urbanos", a análise permite descrever a trajetória do caso e identificar as contradições geradas ao longo do processo. Em termos metodológicos, a investigação foi conduzida mediante narrativas, escala espacial, recorte temporal, questionamentos e conceitos. A experiência coletiva observada parece requerer um novo processo para produzir um espaço público democrático. 


\section{Introducción}

En los escenarios de la vida pública de la ciudad de São Paulo, la apropiación y los usos de los espacios urbanos al principio del siglo XXI han sido marcados por nuevos énfasis. El uso de la bicicleta, el plantío de huertos comunitarios y la organización de fiestas callejeras, son fenómenos que encuentran fuerza en las acciones de colectivos y movimientos activistas. Grupos que desean reflexionar sobre cuestiones cotidianas y buscan nuevas formas de construcción de sentido para la ciudad. Concebidos de manera autónoma, los espacios urbanos son reinventados colectivamente para el uso común. En el ámbito del urbanismo y en los espacios de transformación urbana, ese escenario ha sido considerado por diversos autores, entre ellos Sandler (2020), Carvalho et al. (2019), Hori (2018), Maziviero y Almeida (2017) y Marino (2019).

Este artículo tiene como enfoque particular de investigación la lucha por la transformación de un terreno privado en un parque público urbano: el Parque Augusta, que en la metrópoli es un caso raro de la resistencia ciudadana a la primacía de los intereses económicos en la construcción urbana. Ubicado en el centro de la ciudad, esa demanda ha sido reclamada por grupos de vecinos y activistas de diversos idearios, que unificaron sus agendas en el contexto de las manifestaciones de junio del 2013, ${ }^{1}$ con el objeto de transformar el viejo solar en un parque público. En conjunto, promueven un intenso proceso de resistencia y ocupación, adoptando tácticas de manifestación en forma de ocupaciones y festivales de arte y cultura. La lucha por la causa es antigua, y tanto el reclamo como el uso del espacio por parte de los vecinos, son anteriores a la creación de los movimientos institucionalizados.

Dichas prácticas colectivas son propias de un activismo a pequeña escala, desde el punto de vista ideológico, se caracterizan por una apropiación comunitaria, colaborativa y no partidista; desde el punto de vista del contenido, actúan mediante una programación centrada en el arte y en la cultura; desde el punto de vista de la sociabilidad, por el formato de reunión social — picnics, fiestas y festivales-; y, desde el punto de vista de la acción efectiva, por el activismo de acción directa. Infringen leyes y regulaciones actuales, son insurgencias a escala local practicadas por activismos incipientes que expresan - de formas contradictorias y no articuladasun gran descontento con los usos y las prácticas actuales en la ciudad.

Por otra parte, el análisis del caso permite describir la trayectoria e identificar las contradicciones generadas a lo largo del proceso. El objetivo muy preciso del activismo facilita la convergencia de intereses y la creación de una coalición propicia para su promoción, basada en la preservación del medio ambiente y en los intereses colectivos. Sin embargo, las diferencias reprimidas durante la toma de consenso
${ }^{1}$ En el Brasil del 2013, una serie de movilizaciones ciudadanas pacíficas ganaron fuerza a partir de discusiones en las redes sociales y tuvieron el cuerpo ciudadano presente en el espacio público como instrumento de resistencia. Ambientes semejantes del contexto de la crisis de representatividad politica se han observado en las protestas de España entre el 2009 yel 2015, conocidas como "Indignados" $y$, en Nueva York, el movimiento "Occupy Wall Street" en el 2011 .

territarios 44 213 
surgen como incoherencias del proceso y de límites en los resultados prácticos, un hallazgo que expone la desproporción entre los poderes del activismo local y el proceso capitalista de transformación territorial.

Con base en dicho contexto, este artículo analiza el caso como un fenómeno social y un proyecto de autoconstrucción del territorio, señalando los desafíos de una disputa social que involucra - por parte de activistas, residentes locales y la sociedad civil como un todo-, tácticas efímeras en el contexto de la vida cotidiana y la resignificación del espacio urbano. En ese sentido, el trabajo plantea y discute las siguientes preguntas: ¿Cómo la acción colectiva de vecinos y activistas afecta el proceso de producción y transformación urbana? ¿La institucionalización de los grupos limita o amplía su libertad de acción? ¿Cuáles son las contradicciones creadas y expuestas a lo largo del proceso de disputa?

Figura 1. Embargo del terreno del Parque Augusta

territarias 44

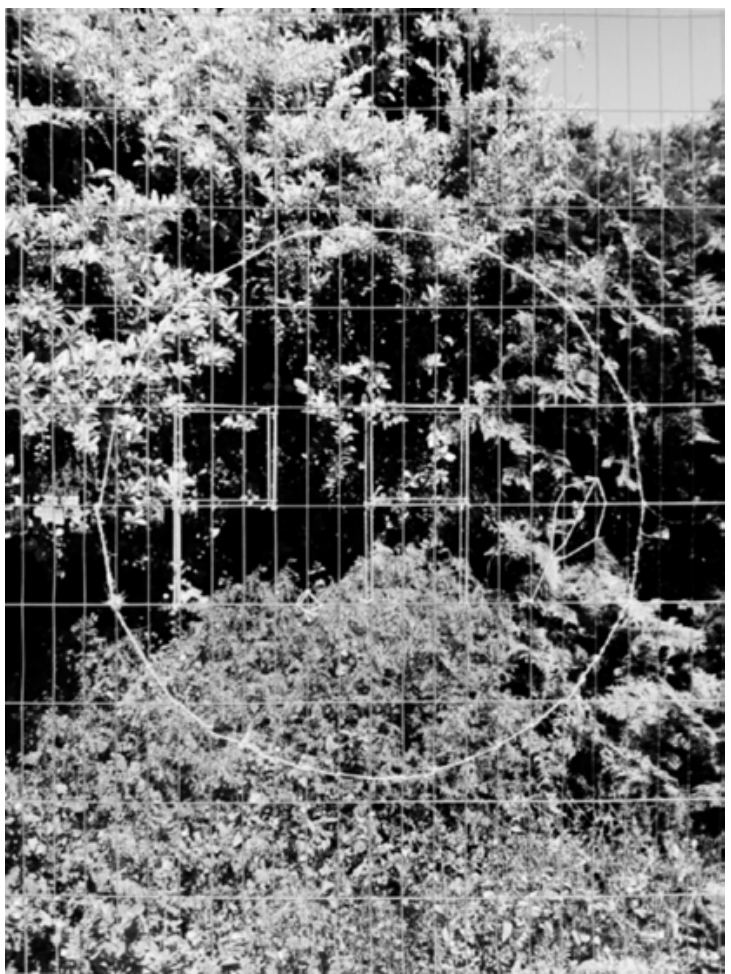

Fuente: Guerra (2014). 
La investigación forma parte de un trabajo más amplio, realizado en el marco de una tesis doctoral en Arquitectura y Urbanismo $^{2}$ que propone una reflexión sobre la apropiación de los espacios urbanos al comienzo del siglo XXI en la ciudad de São Paulo. La metodología que estructura el análisis busca articular dos áreas principales: (i) las narrativas y las acciones de los grupos que forman el movimiento, por medio de entrevistas en profundidad con los actores involucrados y los documentos que produjeron; y (ii) las nociones y conceptos relacionados con los posibles usos del espacio público, así como la estrategia particular y específica de apropiación del espacio urbano. El análisis desde el enfoque espacial y temporal también se fundamenta en diversos documentos oficiales de la administración pública como leyes, informes y procesos administrativos.

En el escenario de conflictos sociales, disputas políticas y apropiaciones juguetonas, aquí se llama "ciudad en fiesta, ciudad en disputa" a un fenómeno que surge para nuevas coreografías sociales de la acción política en el contexto urbano.

Además de esta breve introducción, el artículo tiene dos partes y una conclusión. La primera sección trata temas que, aunque no estén directamente relacionados al movimiento pro Parque Augusta, son esenciales para comprender el objeto de esta investigación: el concepto de los "comunes urbanos" y la lucha por el derecho a la ciudad. La segunda parte expone el tema ambiental en la ciudad de São Paulo, el instrumento de Transferencia Potencial Constructiva (TPC), ${ }^{3}$ los diversos actores sociales involucrados en el reclamo, la interlocución con el poder público y el contexto de la transformación urbana. Por último, la conclusión presenta las ambigüedades, los problemas enfrentados, y un análisis crítico del contexto, que parece requerir nuevos procesos para producir espacios efectivamente ciudadanos.

\section{Cuestiones teóricas}

\section{Del devecho a la ciudad a los comunes urbanos}

Al plantear la expresión "derecho a la ciudad", Henri Lefebvre (1968) abrió el camino para pensar en la ciudad o en la urbanización no solo como un subproducto de la industrialización, sino como un apoyo para la emancipación humana. El término surgió en el contexto de las manifestaciones de mayo de 1968 en París, en el campo libertario abierto por movimientos estudiantiles y ocupaciones populares de fábricas. Destinado a convertirse en un tema más relevante en la lucha de clases, el concepto es planteado del siguiente modo:

El derecho a la ciudad se manifiesta como una forma superior de derechos: el derecho a la libertad, a la individualización en la socialización, al hábitat y al habitar. El derecho a la obra - la actividad participante - y el derecho a la apropiación — muy distinto
${ }^{2}$ Para más información sobre la tesis doctoral titulada "Cidade em festa, cidade em disputa: ativismo e apropriação do espaço urbano em São Paulo no início do século XXI", de la cual el presente trabajo forma parte, véase Marino (2018).

${ }^{3}$ Según el Estatuto de la Ciudad -Ley Federal 10.257 del 2001-, la Transferencia de Potencial Constructiva es un instrumento urbanistico destinado a los propietarios de inmuebles en áreas protegidas o previstas como parque, que autoriza la venta del derecho a construir en una propiedad, transfiriéndolo parcial o totalmente para otro terreno.

tersitarios 44 215 
${ }^{4}$ Los preceptos neoliberales se difundieron por primera vez en los Estados Unidos de Ronald Reagan y el Reino Unido de Margareth Tatcher, $y$ se pusieron en práctica en la década de 1980.

\section{territarias 44}

del derecho a la propiedad - están implicados en el derecho a la ciudad (Lefebvre, 2001, p. 134).

Durante varias décadas, la idea del "derecho a la ciudad" sigue viva en las manifestaciones callejeras y en los movimientos sociales del mundo occidental, que incorporan diversos reclamos - vivienda, escuela, transporte, saneamiento, entre otros - y el derecho a una vida social (Lefebvre, 1968; Castells, 1979). Esta es una ampliación de las expectativas ofrecidas por el llamado Estado de Bienestar Social, que se ha estructurado desde finales del siglo XIX y establece mecanismos de reciprocidad, ayuda mutua y división de la producción. Aunque el modelo se ha organizado completamente solo en algunos países europeos, puede ofrecer en el campo ideológico del capital una alternativa estatal dirigida a la promoción social, sea en la provisión de servicios fundamentales o en la organización de la producción económica.

Con el final de la Guerra Fría en la década de 1990, comenzó un nuevo periodo de hegemonía neoliberal ${ }^{4} \mathrm{y}$, un marcado cambio en la dinámica socio-políticoeconómica occidental abrió espacio a una configuración que empujaba las ambiciones democráticas hacia la resistencia. Cuando empezó el siglo XXI, ya eran hegemónicos los nuevos aspectos socioeconómicos - la concentración de la riqueza y el aumento de la pobreza-, legales — garantía de la eficiencia y la protección del mercado-y ambientales - la explotación excesiva de los recursos naturales-, todos ellos, fuertemente amalgamados unos con otros. A nivel político, varios países retrocedieron en sus procedimientos democráticos (Harvey, 2012; Rolnik, 2015; Sassen, 2014; Piketty, 2014; Diamond, 2015).

La crisis económica del 2008, que a partir de los países adinerados se difundió sistémicamente, abrió espacio en los años posteriores para muchas demandas del campo democrático, ganando expresión en cientos de manifestaciones callejeras en las principales ciudades de los cinco continentes. Las nuevas tecnologías de la información, en especial, Internet móvil, permitieron nuevos modos de activismo, generando un espacio híbrido entre la movilización virtual y la propiedad urbana (Bauman \& Mauro, 2016; Castells, 2017; Santos, 2015; Žižek, 2012). A diferencia del ciberactivismo “de sillón”, hay grupos que se dirigen a las acciones colectivas donde las ocupaciones comunitarias son un instrumento de resistencia (Di Felice, 2012).

Retomando las cuestiones de Henri Lefebvre (1968), David Harvey (2012, 2014) explica el papel crucial de la urbanización dentro del sistema reproductivo al absorber el capital excedente en todos los rincones del mundo. En un contexto en el que el derecho a la ciudad se individualiza y se otorga como valor de venta - la experiencia urbana es exclusiva para los que tienen dinero-, la unificación de las demandas fragmentadas de acceso a las 
ofertas urbanas se convierte en un proyecto político emancipador. Según Harvey, los ciudadanos obtienen el derecho colectivo de dar forma a la ciudad a través de un mayor control democrático sobre el capital excedente empleado en la urbanización. Con su idea de coproducción territorial, Harvey replantea la expresión "derecho a la ciudad". Si las ciudades se convierten en mercancías, el autor señala dialécticamente la fuerza contraria presente en la agenda transformadora de la comunidad ciudadana.

Así, al reforzar el carácter emancipador de la expresión planteada por Lefebvre (1968), David Harvey $(2012$; 2014) propone una redefinición del concepto:

El derecho a la ciudad es por tanto mucho más que un derecho de acceso individual o colectivo a los recursos que almacena o protege; es un derecho a cambiar y reinventar la ciudad de acuerdo con nuestros deseos. Es además, un derecho más colectivo que individual, ya que la reinvención de la ciudad depende inevitablemente del ejercicio de un poder colectivo sobre el proceso de urbanización. La libertad para hacer y rehacermos a nosotros mismos y a nuestras ciudades es, como argumentaré, uno de los más preciosos pero más descuidados de nuestros derechos humanos (Harvey, 2012, p. 74).

La resignificación conceptual de Harvey (2012), tiene una gran influencia de Foucault (1979) que busca su esencia en las prácticas de luchas sociales. Históricamente, los movimientos colectivos han luchado de manera fundamental para fortalecer los servicios públicos, la seguridad social y el derecho al trabajo. Con la crisis del Estado regulador, cuando su acción para calmar la desigualdad estructural del capitalismo es limitada o agotada, surge una nueva dinámica que se centra en la gestión colectiva. Una de sus características es la lucha para evitar la transformación de bienes comunes en propiedad privada y, en consecuencia, en bienes capitalistas que impiden su uso social. Indispensables para la vida democrática, los bienes comunes incluyen, además de espacios y bienes públicos, los bienes naturales esenciales de la vida humana - aire, agua, sol, ríos, bosques, etcétera-, muchos de ellos, bajo el riesgo de ser extintos o privatizados (Hardt \& Negri, 2016; Bollier, 2016).

En un estudio de la década de 1990, Elinor Ostrom ${ }^{5}$ propuso que los bienes comunes - hasta ahora vistos como recursos no renovables en constante degradación-, deberían ser controlados por la comunidad local, una solución de gestión alternativa a aquella estrictamente pública o privada (Ostrom, 1990). Según la autora, esta preocupación es similar a abordar otras necesidades colectivas: "comunes urbanos", que incluyen bienes y servicios públicos como parques, transporte, sistemas de saneamiento, recolección de residuos, universidades y escuelas públicas (Dardot \& Laval, 2017; Bollier, 2016; CastroComa \& Martí-Costa, 2015; Harvey,
${ }^{5}$ Elinor Ostrom fue pionera en publicar sobre lo común en la década de 1990. La economista politica estadounidense, ganadora del premio Nobel en el 2009 por su trabajo, hizo un análisis empirico de estudios de caso centrados principalmente en la gestión económica, legal y administrativa de lo común.

tersitarios 44 217 
${ }^{6}$ El término se refiere a parcelas agricolas de gestión privada que surgieron en las tierras comunales de Inglaterra desde el siglo XVI, como proceso de privatización de los bienes comunes.

territarias 44 218
2012). Además, la indefinición de lo que es exactamente el espacio público permite que se produzca la apropiación de ciertos territorios, sea cual sea su situación legal (Paquot, 2010). La adhesión colectiva - espontánea o articulada- a la práctica de apropiación democrática que ignora la condición jurídica, contribuye a la expansión de la noción de espacio público acercándola al lugar simbólico de expresión y debate político definido en 1962 por Habermas (1984).

Después de haber estudiado ampliamente el concepto, Pierre Dardot y Christian Laval (2017) afirman que lo común - al imaginar una nueva forma de vida autogestionada - trasciende a las banderas sociales tradicionales. A menudo, en lugar del rescate estatal de la propiedad privada, aboga por el fin de la gestión burocrática — privada o pública- a favor de una gestión social colectiva. Entonces, construir un nuevo tipo de ciudad desde el interés común es el nuevo desafío. Lo común como principio político que debe instituirse $-\mathrm{y}$ no atribuirse - como un acto constante de apropiación y de autogestión: es decir, un acto común. Al proponer un poder político comunitario basado en la lucha permanente, el movimiento de los comunes ya no ve al Estado como el único instrumento de defensa y regulación del mercado (Rancière, 2010).

El límite de esta comprensión se da en las dificultades para perpetuar e institucionalizar los logros de los colectivos en su constante enfrentamiento con las fuerzas antagónicas en la lucha por la ciudad. Así, es posible señalar por lo menos tres contradicciones en el desempeño actual de los comunes: el desajuste entre las escalas urbanas, cuando una buena solución local no es una buena respuesta territorial; la ineficacia de la gestión horizontal, cuando la toma de decisiones es lenta, sin tener en cuenta el momento adecuado para la acción (Harvey, 2014); y la cooptación de la producción de los bienes comunes como proceso de cercamiento, ${ }^{6}$ puesto que el espacio público tiene su uso restringido y se presenta como una negación del espacio político (Dardot \& Laval, 2017; Hardt \& Negri, 2016; Harvey, 2014).

\section{El Parque Augusta en São Paulo}

\section{El tema ambiental en São Paulo: el parque urbano}

Durante el rápido crecimiento de São Paulo en el siglo Xx, el aspecto ambiental se ha descuidado, y con ello, han prevalecido dos patrones de ocupación opuestos: áreas de preservación concentradas en los bordes de la ciudad y áreas verdes ausentes en su interior. Razón por la que se destacan algunos problemas graves: ocupaciones irregulares en las áreas de la Mata Atlántica - principalmente en las colinas y en orillas de las represas-, inundaciones constantes, contaminación atmosférica y del suelo y, saneamiento deficiente (Mello-Théry, 2011; Limnios \& Furlan, 2013). La escasez de parques 
dentro de la ciudad es sorprendente. De los únicos 30 parques públicos municipales implementados en São Paulo hasta 1996, solo $4^{7}$ se originaron de terrenos estatales. Los demás fueron concebidos de manera aislada, a partir de tierras privadas: 13 unidades por ley de parcelación de sue$10^{8}$ y 13 por expropiación (Kliass, 1993; Bartalini, 1996).

Solamente a partir del Plan Director Estratégico del 2002, el sistema de áreas verdes se convirtió en un elemento estructurante de la planificación urbana de São Paulo. Alentada por programas del Gobierno Federal, la estrategia municipal prioriza la recuperación ambiental de los cursos de agua y fondo del valle para la creación de parques lineales, una iniciativa que requiere una fuerte articulación intersectorial. De 32 parques públicos existentes en el 2007, el municipio saltó a 107 en el 2019. De los parques creados después del Estatuto de la Ciudad, ${ }^{9}$ una gran parte se originó en áreas de basurales, de recuperación de orillas de ríos y arroyos, y de áreas de expropiaciones (Macarrão, 2009).

Previsto en los planes directores del 2002 y el 2014, el mecanismo de TPC no se usó para la creación de parques públicos sino hasta el 2018. Aunque utilizado ampliamente en la preservación del patrimonio histórico construido, en el caso de la solicitud para la implementación de parques urbanos, la transferencia implicaría la donación de la propiedad que se haría pública.

Figura 2. Terreno en disputa para implementación del Parque Augusta

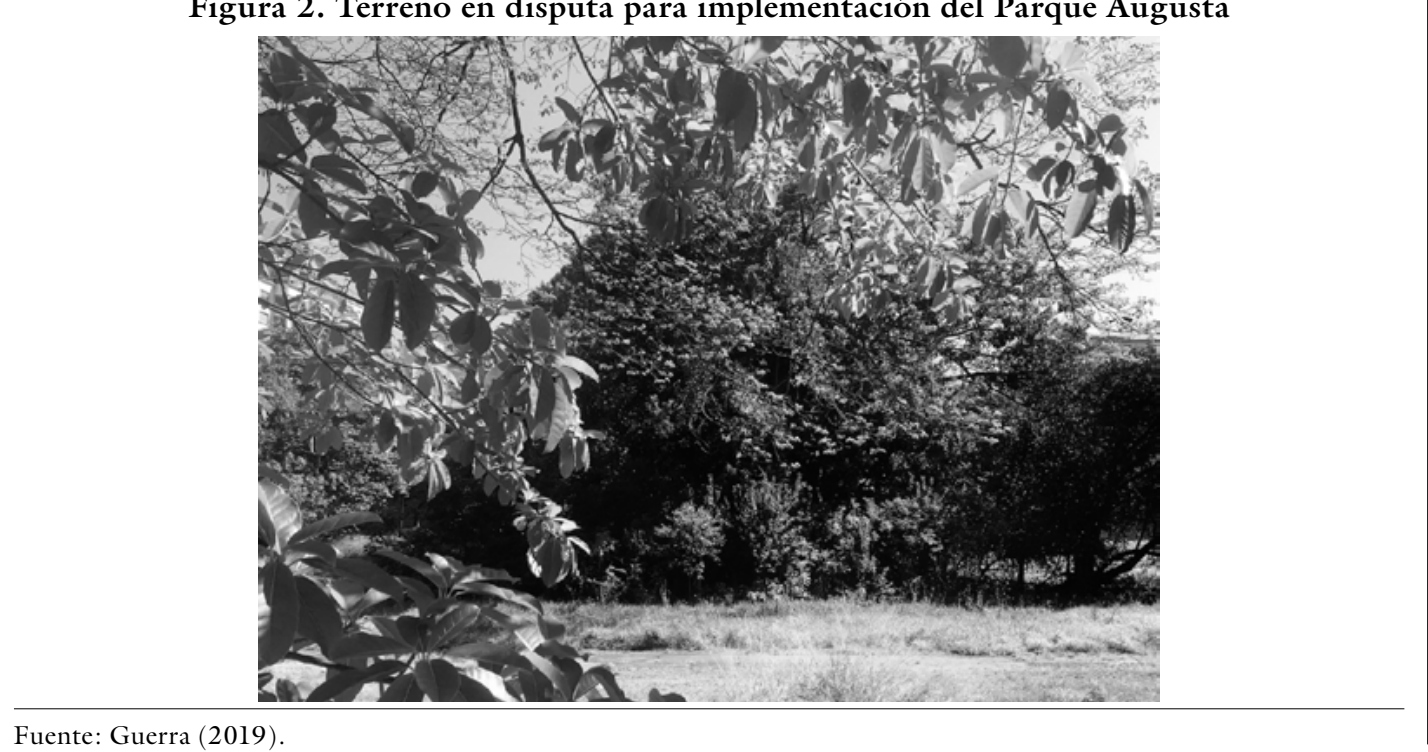

Fuente: Guerra (2019).

Ciudad en fiesta, Ciudad en disputa: el caso del Parque Augusta en São Paulo
Parque Ibirapuera, Parque da Luz, Parque Dom Pedro II y Parque da Independência.

${ }^{8}$ La parcelación de suelo en Brasil se rige por la Ley Federal 6.766 de 1979, que establece la división de terrenos urbanos y prevé la designación de espacios públicos previstos para la implementación de áreas verdes.

${ }^{9}$ Ley 10.257 del 2001 que reglamenta el capitulo "Politica urbana" de la Constitución brasileña.

territarias 44 219 
10 Al analizar diversos informes de diarios y periódicos se observa que el caso ha sido ampliamente divulgado por la prensa.

${ }^{11}$ Las informaciones de registro de compra y venta fueron extraidas de la 5." Escribanía de Inmuebles de São Paulo, matrícula número 12.952.

${ }^{12}$ Los informes oficiales de la administración pública fueron extraidos de los procesos administrativos municipales de número 2014-0.044.262-8 y 2014$0.050 .156-0$.

${ }^{13}$ Las afirmaciones se basan en trabajo de campo y entrevistas profundizadas realizadas por los autores en diversos periodos entre el 2015 y el 2018. Para apoyar el análisis del discurso, se recurrió a transcripciones de audiencias públicas, actas de procesos administrativos, publicaciones en las redes sociales, diarios y revistas.

\section{territorias 44}

\section{El caso del Parque Augusta}

El terreno conocido como Parque Augusta (figura 1 y 2), es una propiedad privada de $24750 \mathrm{~m}^{2}$ que conserva una porción de la Mata Atlántica nativa - un pequeño bosque que ocupa aproximadamente el $40 \%$ de la propiedad- en pleno centro de São Paulo. La historia del lugar está presente en la memoria colectiva y es bastante significativa para la opinión pública. ${ }^{10}$ Desde 1907 hasta fines de la década de 1960, el sitio albergaba una escuela tradicional para niñas - el Colegio des Oiseaux-, el cual era propiedad de la Asociación de Instrucción Juvenil de Mujeres. ${ }^{11}$ Según diversos informes, ${ }^{12} \mathrm{el}$ bosque era mantenido por las monjas de la institución y ello propició su uso público para actividades de ocio.

En 1968, con el objetivo de implantar un emprendimiento inmobiliario, la empresa Teijin do Brasil adquirió el terreno y demolió el edificio histórico. El descontento y la presión de la sociedad civil llevaron a varios decretos de servicios públicos en el área, a la obligación de preservar el bosque y los edificios restantes. En 1974, los propietarios firmaron un Término de Compromiso con la municipalidad, en el cual se les exige a ellos y a sus sucesores, preservar y mantener el libre acceso de la población al sitio. De otro lado, los diversos intentos de los propietarios por hacer emprendimientos inmobiliarios se frustraron $y$, el terreno permanece hasta nuestros días sin nuevas construcciones.
Durante más de cuatro décadas, hasta el 2013 , la propiedad permaneció abierta y fue utilizada como parque por el vecindario.

\section{El punto de vista de la sociedad civil}

Hay cuatro grupos principales que actúan en pro del Parque Augusta: ${ }^{13}$ (i) Sociedade dos Amigos, Moradores e Empreendedores do Bairro de Cerqueira César (Samorcc), una asociación de vecinos creada en el 2001 que trabaja con diferentes demandas en la región; (ii) Aliados do Parque Augusta, también llamado "sos Parque Augusta", un grupo generalmente formado por siete activistas que desde el 2004 se dedican exclusivamente a la causa; (iii) Parque Augusta sem Prédios, un grupo defensor de causas ambientales e indígenas; y (iv) Organismo Parque Augusta (OPA), movimiento horizontal y autogestionado que empezó en las manifestaciones del 2013. Así mismo, se nota la presencia de otras subscripciones, como el Movimento Parque Augusta — que designa la coalición de algunos grupos-, y también la $A u$ togestão Parque Augusta, denominación creada durante el momento de la ocupación colectiva.

El primer acto de la sociedad civil organizada a favor de la creación del Parque Augusta se produjo en el 2001, cuando la Samorcc organizó una petición solicitando la implementación de ese parque público a la municipalidad. El documento reclama un Parque Augusta 
libre de edificios, preservando el medio ambiente. Más adelante, en una audiencia pública, la presidenta de la entidad expuso que los propietarios del terreno deberían estar obligados a invertir en la creación del parque (Prefeitura Municipal de São Paulo, 2012).

Aunque la Samorce tenga una postura firme en la defensa de los intereses colectivos en el caso del Parque Augusta, ello no impide que sostenga posiciones conservadoras o teóricamente incoherentes en otras escalas (Harvey, 2014).
En el 2015, por ejemplo, la Samorcc hizo una demanda al Ministerio Público ${ }^{14}$ contra la prohibición de automóviles y la liberación de la Avenida Paulista para actividades de ocio los domingos, una acción proporcionada por el programa municipal Ruas Abertas. En su demanda, la asociación cuestiona al programa con las siguientes quejas: restricción del acceso de vehículos de los residentes, comercio formal y servicios hospitalarios; aumento del crimen y desorden reportado por registros de la policía; aumento de accidentes

Figura 3. Movilización Parque Augusta, segundo semestre del 2013
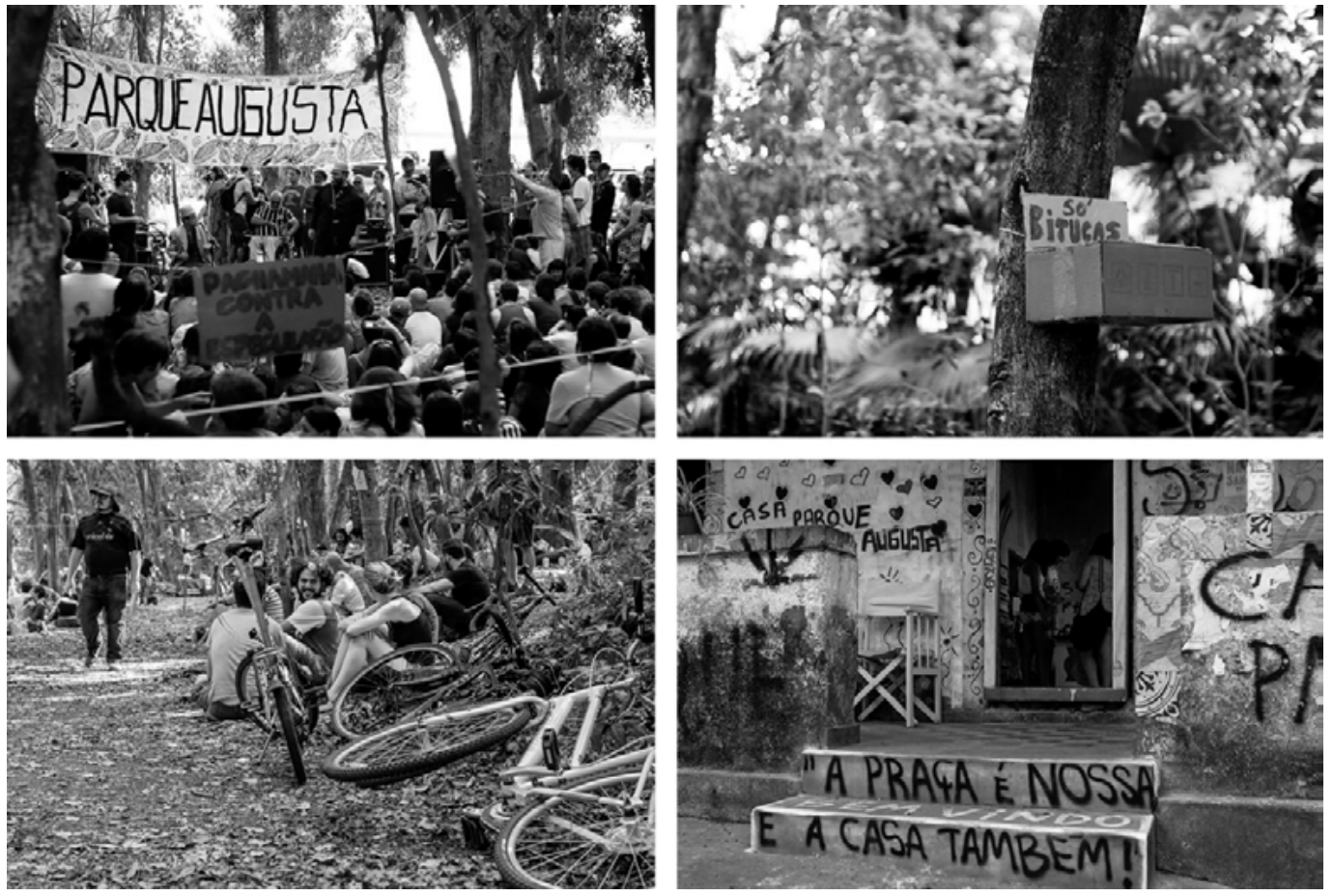

Fuente: Mercadante (arriba, 2014) y Paixão (abajo, 2014).

${ }^{14}$ Investigación civil numero 14.0279.00004/2015-1. La demanda fue reiterada en una carta el 11 de octubre del 2016, enviada al recién elegido alcalde João Doria. 
${ }^{15}$ Los actos fueron organizados en equipo con dos escuelas públicas de São Paulo: Caetano de Campos y Marina Cintra. tersitarias 44 involucrando bicicletas, patinetas y peatones; aumento del comercio informal; mayor número de vendedores ambulantes, personas sin techo y usuarios de drogas; molestia sonora causada por presentaciones musicales (Samorcc, 2016). Al criminalizar la apropiación democrática de la calle, la entidad revela prejuicios arraigados en la mentalidad de una parte de la sociedad de São Paulo que inducen a la segregación urbana (Caldeira, 2000, 2012).

En el 2004, el grupo Aliados do Parque Augusta surgió con el único propósito de reclamar la creación del parque, organizando manifestaciones y actos de apropiación que se llevan a cabo en conjunto con la Samorcc o con la colaboración de escuelas públicas del vecindario, ${ }^{15}$ en la cual estudiantes y maestros desarrollan un trabajo educativo sobre el ejercicio de la ciudadanía y la preservación del medio ambiente. El grupo también creó el acto de apropiación anual "Picnic en el asfalto" o "Picnic a la antigua", que reúne a los demás grupos que actúan por la causa. Ese día, los activistas llevan canastas con comida y toallas que se extienden frente al parque, en la calle y en el asfalto. Con presentaciones de música en vivo y otras actividades artísticas, la acción permite una apropiación efectiva del terreno, más allá de su situación legal (Paquot, 2010).

En el 2006, en una acción conjunta con Samorcc, el grupo Aliados do Parque Augusta alcanzó las 15000 firmas y obtuvo el apoyo de los concejales Juscelino Gadelha y Aurélio Nomura, quienes propusieron la creación del parque con el Proyecto de Ley 345 del 2006. Aunque no haya sido sancionada en ese momento,

Figura 4. Carteles y grafiti de movimientos pro Parque Augusta
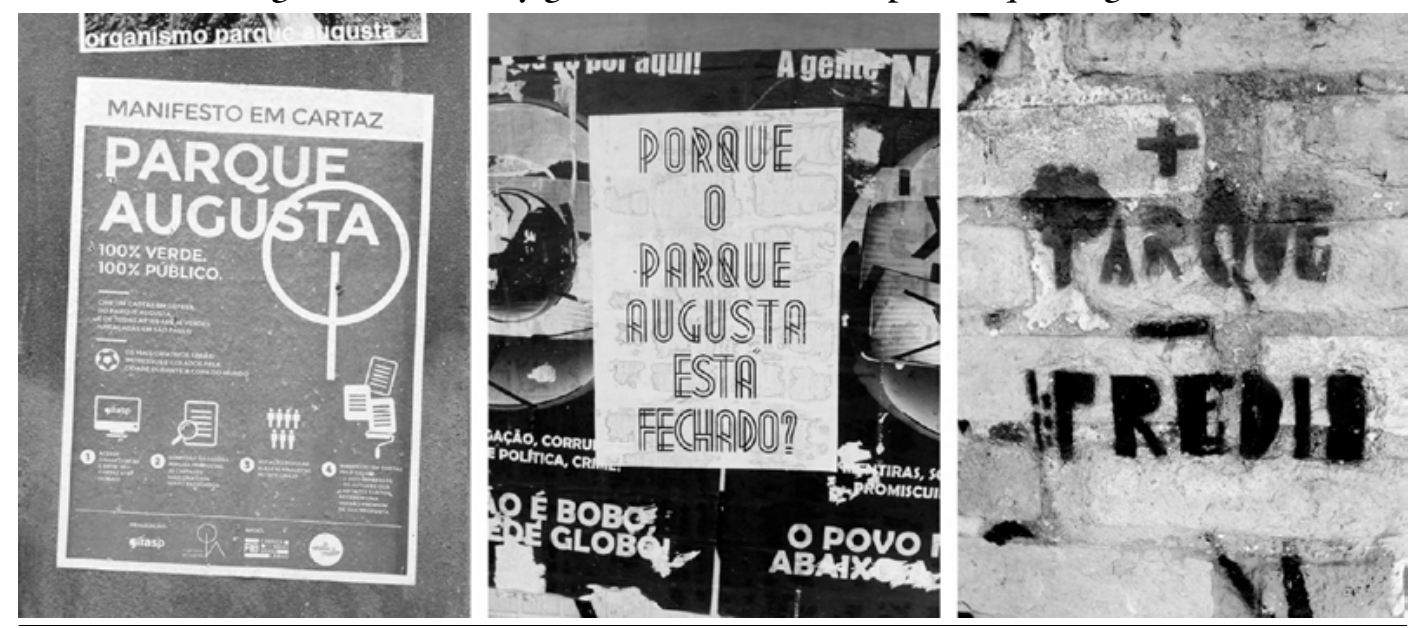

Fuente: Guerra (2014). 
la propuesta se convirtió en la base de la Ley 15.941 del 2013 que, como se verá a continuación, fue aprobada años después.

En una audiencia pública celebrada en el 2012, un activista del grupo Aliados do Parque Augusta hizo una denuncia contundente sobre la lógica exclusivamente lucrativa de las constructoras (Prefeitura Municipal de São Paulo, 2012). En agosto del 2013, en una entrevista el mismo activista advirtió a la prensa que el Decreto de Utilidad Pública (DUP) ${ }^{16}$ expiraría, y, propuso entonces que los costos de la implementación del parque se financiaran a cargo de los residentes del vecindario - sus principales beneficiarios-, con el aumento del Impuesto sobre la Propiedad Predial y Territorial Urbana (IPTU) (Rosati, 2013). Es interesante notar que la propuesta busca una solución colectiva para mantener el uso social del terreno, como una alternativa a la implementación o acción estrictamente pública (Ostrom, 1990; Dardot \& Laval, 2017; Bollier, 2016).

El Parque Augusta sem Prédios es un movimiento de activistas que luchan por diversas causas no solo de resistencia urbana, sino también ambientales e indígenas. Entre ellas: la demarcación de las tierras guaraníes; en contra de las prácticas mineras que incurren en delitos ambientales como en Mariana y en Brumadinho, $\mathrm{Mi}$ nas Gerais; y por la creación de parques y espacios públicos en São Paulo, como los Parques Augusta, Bixiga y Búfalos. Dicho grupo a menudo utiliza tácticas de manifestación performática, como el Parque Aquático Móvel en asociación con el colectivo Secura Humano, que consistió en instalar piscinas y duchas en la calle Augusta enfrente al terreno en disputa. En septiembre del 2017, también organizaron el primer festival de performance a favor del Parque Augusta.

En las manifestaciones de junio del 2013, el espacio público vio el activismo crecer con fuerza y miles de personas salieron a las calles para defender el derecho a la ciudad. En ese escenario, un grupo de jóvenes exigió la preservación total de esa zona verde, que es una de las últimas de la región central de São Paulo. Ese es el origen del movimiento Organismo Parque Augusta (OPA), un grupo de resistencia urbana de toma de decisiones autogestionado y horizontal, que se organiza a partir de grupos de trabajo para promover acciones directas en la calle, difundidas a través de Internet, en especial por Facebook. De manera estratégica, el grupo celebra sus asambleas semanales en el propio Parque Augusta y, mientras el terreno permanece cerrado, a 200 metros de ahí, en la Plaza Roosevelt.

La primera fase de acción del movimiento empezó los días 7 y 21 de diciembre del 2013, cuando los manifestantes realizaron dos actos de apropiación del terreno para dar visibilidad a la cuestión de la creación del parque, como se puede observar en las figuras 3 y 4 . Así, se han producido fiestas y festivales con espectáculos, debates, comidas, obras de
${ }^{16}$ La declaración de utilidad pública es un acto administrativo que dispone sobre expropiación por utilidad pública. tersitarios 44

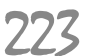


${ }^{17}$ Fernando Haddad fue alcalde de la ciudad de São Paulo por el Partido de los Trabajadores entre el 2013 y el 2016.

${ }_{18}$ Aparte del uso recreativo $y$ de ocio en el terreno, desde 1993 operaba un estacionamiento privado en una parte cementada junto a las calles Augusta $y$ Caio Prado.

${ }^{19}$ En el contexto de la alarmante crisis hidrica en São Paulo.

\section{territarias 44} 224 teatro, talleres, entre otras actividades con el sentido de agregar activistas en la lucha. En respuesta, el 23 de diciembre del 2013 fue sancionada por el alcalde Fernando Haddad $^{17}$ la Ley Municipal 15.941, que propone la creación del Parque. El 28 de diciembre, como reacción, las constructoras Setin y Cyrela cerraron las puertas del terreno, imposibilitando las actividades. ${ }^{18}$ Una situación que se mantiene hasta hoy: como negación al espacio político, se ha restringido la utilización del espacio de uso público (Dardot \& Laval, 2017; Hardt \& Negri, 2016; Harvey, 2014).

La oficialización del movimiento espontáneo del 2013 ocurrió justamente en el momento del cierre del terreno. Sin embargo, durante el 2014, el Organismo Parque Augusta siguió operando dentro y fuera del terreno. El 19 de abril el evento Ciranda Livre ocurrió en el terreno restringido, pero aún sin el control de seguridad de las empresas constructoras que prohíben el uso del área. El 2 de junio, el grupo lanzó el primer número de la Revista do Organismo Parque Augusta (Organismo Parque Augusta, 2014), que revela los principios del movimiento - primacía pública, respeto, generosidad, transparencia, democracia directa, ciudadanía mundial, horizontalidad y pluralismo- y la idea del espacio como laboratorio de prácticas urbanas - ambientales, educativas, culturales y sociales-, asegurando la existencia del verde en lo urbano, con prácticas de permacultura, jardines, clases de yoga, presentaciones artísticas, cine, festivales y actividades autogestionadas. Otros números de la $R e^{-}$ vista do Organismo Parque Augusta fueron publicados por el movimiento Organismo Parque Augusta, en un periodo de tiempo que caracteriza su fase más creativa.

Como instrumento urbanístico para la implantación del parque, el grupo sugiere la desapropiación no onerosa por medio de una TPC. En marzo del 2014, ${ }^{19}$ para fortalecer su agenda ambiental urbana, el grupo Organismo Parque Augusta promueve el primer acto público en defensa de los parques amenazados de São Paulo, culminando en la creación de un movimiento de agenda más amplio, llamado Rede Novos Parques SP. Así, concentran una agenda que agrega alrededor de 50 movimientos locales dentro de una red de reclamos ambientales en el municipio.

El 17 de enero del 2015, los activistas abrieron las puertas del parque que estaban cerradas desde diciembre del 2013 y ocuparon el área con una vigilia de protesta (figura 5). Entre otras cosas, el movimiento acusó a los propietarios de delitos ambientales y denunció el acto de impedir el acceso público como algo ilegal. La ocupación de carácter político y cultural, recibió el nombre de Verão Parque Augusta. La acción obtuvo el apoyo de grupos internacionales involucrados en la lucha por el derecho a la ciudad, como el movimiento "Indignados" de España y los activistas del Parque Gezi de Estambul, quienes visitaron el Parque Augusta a finales del 2014 en el intercambio de 
Figura 5. Ocupación Verão Parque Augusta, 18 de enero del 2015
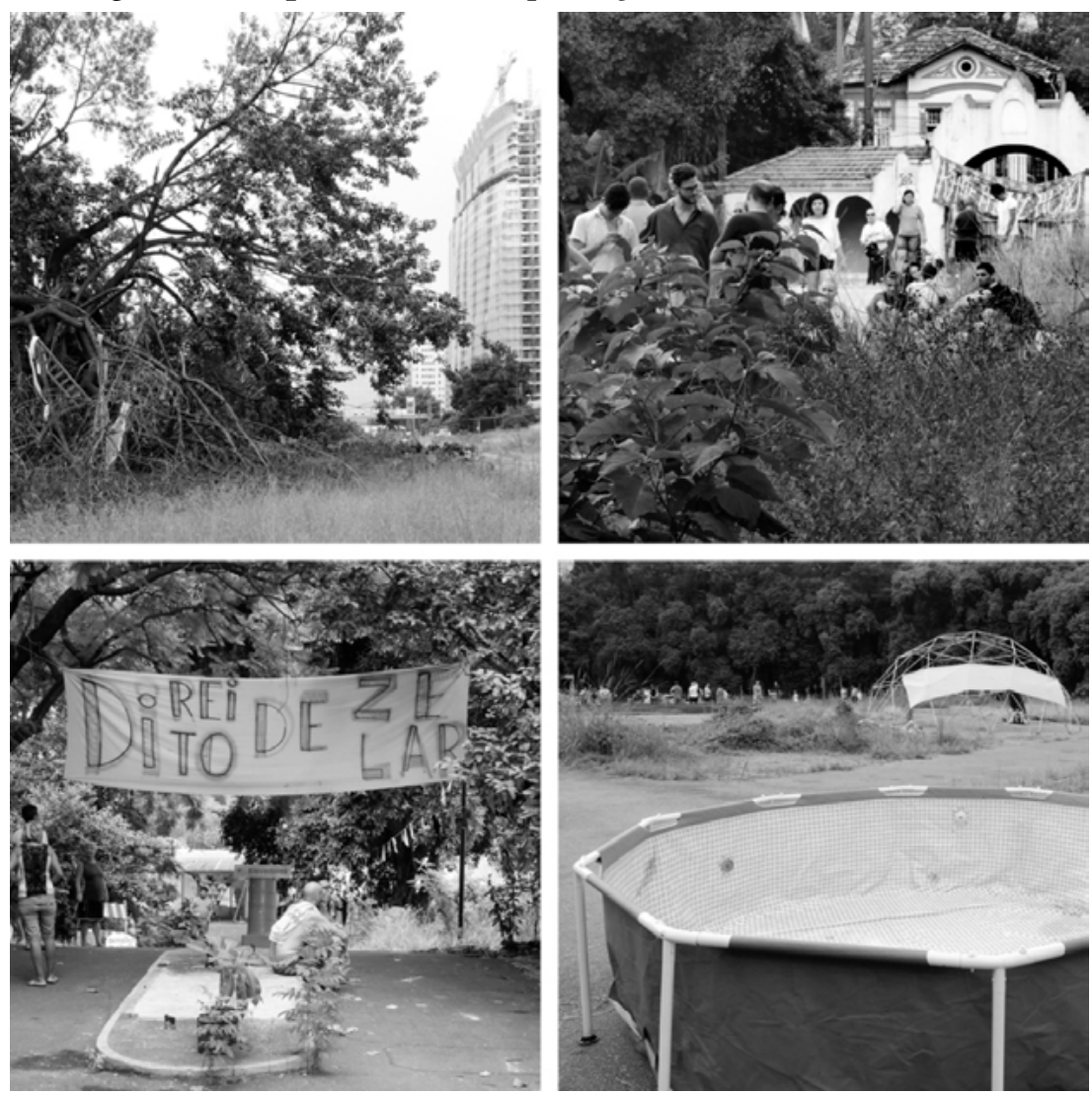

Fuente: Marino (2015)

experiencias desde la ocupación cultural de espacios ociosos, hasta formas de resistencia contra posibles actos de violencia policial. ${ }^{20}$

Entre el 17 de enero y el 4 de marzo del 2015, los activistas estuvieron acampando en el terreno hasta que se produjo la acción de desalojo (figura 6). Ante la resistencia de cuatro activistas, la policía reaccionó con violencia, pese a que la mayoría del grupo había marchado pacíficamente hacia la municipalidad. Al día siguiente, las empresas de construcción perforaron las aceras e instalaron un revestimiento para aislar aún más el terreno - una acción autorizada por la municipalidad-. En una entrevista dada a la revista Carta Capital el 6 de marzo de dicho año, el empresario Antonio Setin explicó que "el bosque y las puertas restantes del Colegio des Oiseaux
${ }^{20}$ Para enfrentar la crisis del agua de São Paulo en marzo del 2014, el grupo Organismo Parque Augusta se articuló en la creación de una agenda ambiental más amplia en torno a la Rede Novos Parques SP.

tersitarios 44

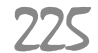


${ }^{21}$ Es decir, de la capital del estado de São Paulo, que es la ciudad homónima.

22 Investigación civil PJPP-CAP número 121/2015, Acción Civil Pública en el 100921414.2015.8.26.0053.

${ }^{23}$ Artículo 1 del Decreto Municipal 10.766, sancionado el 7 diciembre de 1973.

${ }^{24}$ De acuerdo con los registros 12.952 y 12.953 de la 5. ${ }^{a}$ Escribania de Registro de Inmuebles.

${ }^{25}$ Por medio de la Resolución 23 del 2004, definida por el Departamento de Patrimonio Histórico Municipal.

\section{territarias 44}

son considerados patrimonio histórico, pero están en una propiedad privada" (Setin, 2015).

Si el objetivo de la ocupación era dar visibilidad a la causa y consolidar la idea del parque público en el imaginario colectivo de la ciudad, la reacción de los propietarios demuestra el desafío de construir una ciudad a partir del interés colectivo, de modo independiente y sin considerar la propiedad privada como valor máximo. Cuando se trata de bienes comunes urbanos, hay mucho por hacer desde el punto de vista práctico, pero también conceptual (Ostrom, 1990; Harvey, 2012; Hardt \& Negri, 2016; Dardot \& Laval, 2017).

Después de la acción de desalojo, el Ministerio Público buscó a los activistas. La Fiscalía del Patrimonio Público y Social de la Capital ${ }^{21}$ instituyó una Investigación Civil $^{22}$ para indagar violaciones de la legislación ambiental, daños al patrimonio histórico y a la vegetación protegida. En ese momento, con el cambio en la estrategia de actuación, el movimiento del Organismo Parque Augusta se transformó: pasó de un perfil joven y artístico, a un grupo más maduro y técnico.

\section{El punto de vista del poder público}

Si la población ha utilizado el área durante mucho tiempo como parque, y si los movimientos han luchado por la causa durante años, la administración municipal también ha manifestado su interés en el uso público del área en ese periodo. En 1973, con la demolición del edificio Vila Uchoa que albergaba las actividades del Colegio des Oiseaux, el terreno se convirtió en objeto de varios decretos de preservación y términos de compromiso que lo caracterizan en la práctica como de interés público. El Decreto de Utilidad Pública 10.766 de 1973, obliga al propietario a "preservar completamente las áreas verdes existentes en la propiedad, mantenerlas, conservarlas y expandirlas cuando sea posible" y, además, "permitir, de acuerdo con las finalidades de aprovechamiento de los respectivos terrenos, el uso público de las áreas verdes". ${ }^{23}$

En 1974, se firmó el Término de Compromiso entre la municipalidad y los propietarios, obligándolos a conservar y mantener el espacio formado por dos inmuebles privados. ${ }^{24}$ En 1989, el área fue caracterizada como patrimonio ambiental por el Decreto Municipal 30.443 de 1989, ampliando el alcance de su preservación. Así, la municipalidad se ocupa de la supervisión de la preservación de los árboles y aplica el Término de Ajuste de Conducta (TAC), que requiere la plantación de $\mathbf{4 5 0}$ árboles más.

Desde un enfoque del patrimonio histórico y ambiental, los remanentes del antiguo colegio fueron decretados como patrimonio histórico en el 2004. ${ }^{25}$ Además de proteger los elementos más significativos del inmueble — portería, pequeña edificación y área del bosque-; el documento específica las directrices de ocupación de los lotes que componen 
Figura 6. Acción de desalojo del terreno en litigio
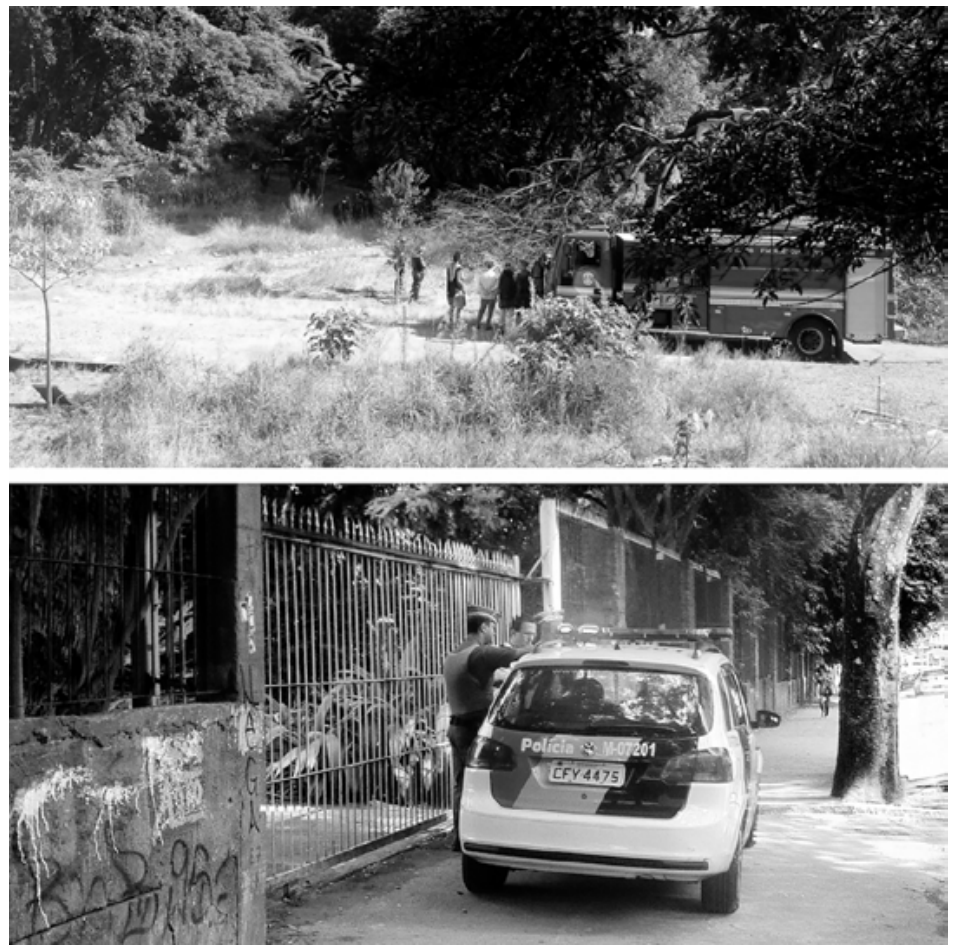

Fuente: Martins (arriba, 2015) y Guerra (abajo, 2015).

el terreno con altura máxima para construcción de 36 y 45 metros en el área estipulada. También, tiene como anexo un levantamiento del conjunto de especies de árboles y de arbustos inventariados.

Además del interés en preservar y garantizar el uso público del patrimonio ambiental, la municipalidad indica el interés en comprar el área. En el 2001, según lo que dispone el Estatuto de la Ciudad, el poder público tiene "preferencia por la adquisición de las propiedades urbanas sujetas a enajenación onerosa entre particulares". ${ }^{26}$ En el 2002, el terreno aparece como un parque en el Plan Director Estratégico (PDE), que también requiere que "las propiedades ofrecidas para la venta $[. .$.$] necesariamente deben$ ofrecerse a la municipalidad, que tendrá preferencia para la adquisición por un periodo de cinco años". ${ }^{27} \mathrm{Y}$ en el 2004 , como consecuencia de esta propuesta, el Plan Regional Estratégico de la Subprefectura de la Sé ${ }^{28}$ indica el área de incidencia del derecho preferencial de compra - ley vigente hasta el 2008 - , con el objetivo
${ }^{26}$ Artículos 25, 26 y 27 de la Ley Federal 10.257 del 10 de julio del 2001.

27 Conforme Articulo 205 de la Ley Municipal 13.430 del 2002, que dispone sobre el Plan Director Estratégico, coordinado por el arquitecto Jorge Wilheim.

${ }^{28}$ Ley Municipal 13.885 del 2004.

tersitarios 44

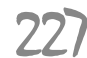


${ }^{29}$ Gilberto Kassab fue alcalde de la ciudad de São Paulo entre el 2006 y el 2012, por el Partido de la Frente Liberal - boy llamado Demócratas-y, a partir del 2011, por el Partido Social Demócrata.

territarias 44 de crear espacios públicos de ocio y áreas verdes. En el 2008, el alcalde Gilberto Kassab $^{29}$ firmó el Decreto de Utilidad Pública (DUP) 49.922, declarando el área como de utilidad pública y prevé su expropiación, pero como el proceso de expropiación no ocurre, el derecho de preferencia caduca finalmente en el 2013, después de 5 años.

Como se ha visto, en la coyuntura de las manifestaciones del 2013 y los actos y ocupaciones en el terreno como respuesta al fortalecimiento del activismo contra la aprobación del proyecto (figuras 7 y 8), se sanciona la ley que propone la creación del Parque Municipal Augusta. A pesar de la aprobación de la ley que crea el parque, la administración del alcalde
Fernando Haddad tenía algunos entendimientos restrictivos sobre el caso: (i) siendo el terreno privado y la región privilegiada por infraestructura pública, no priorizaría aportar recursos públicos para expropiar el área - decisión que se reevalúa más tarde, cuando hay intentos de desapropiación no onerosa y de negociación de valor-y (ii) el proceso de aprobación del emprendimiento privado ya se había iniciado durante la gestión municipal anterior, garantizando por ley a las partes interesadas el derecho de protocolo, así que no se descartaba la posibilidad de implementar el parque en una parte del área del terreno.

La ley sancionada a partir del proyecto de Ley 345 del 2006 - que estuvo tramitando en la cámara municipal desde

Figura 7. Grafiti protesta en la pared del terreno en disputa

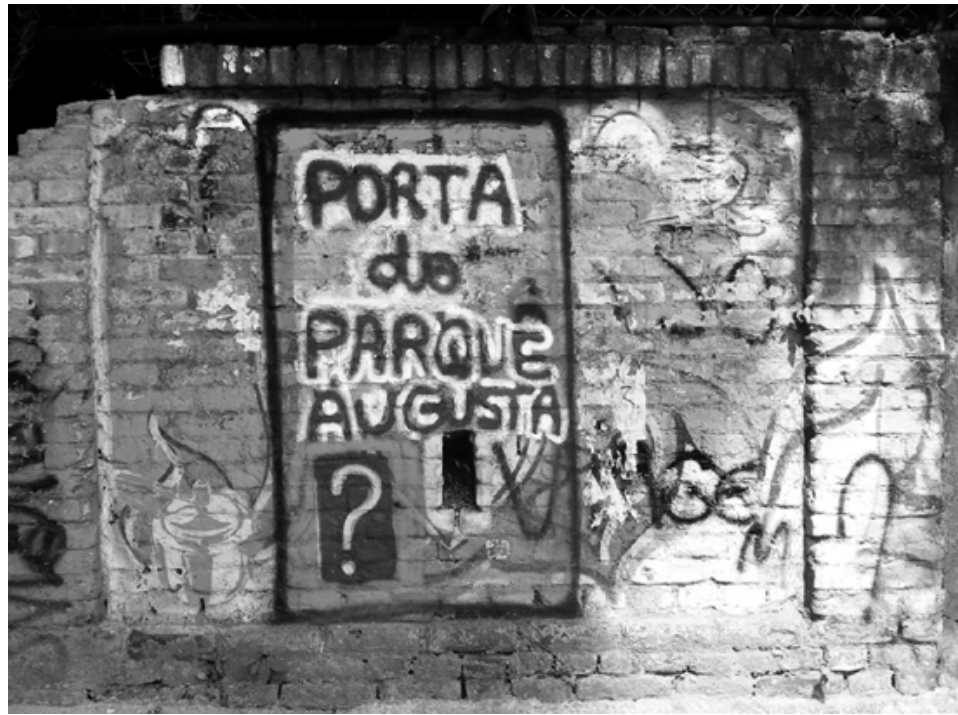

Fuente: Guerra (2015). 
Figura 8. Los manifestantes llevan pancarta pro Parque Augusta

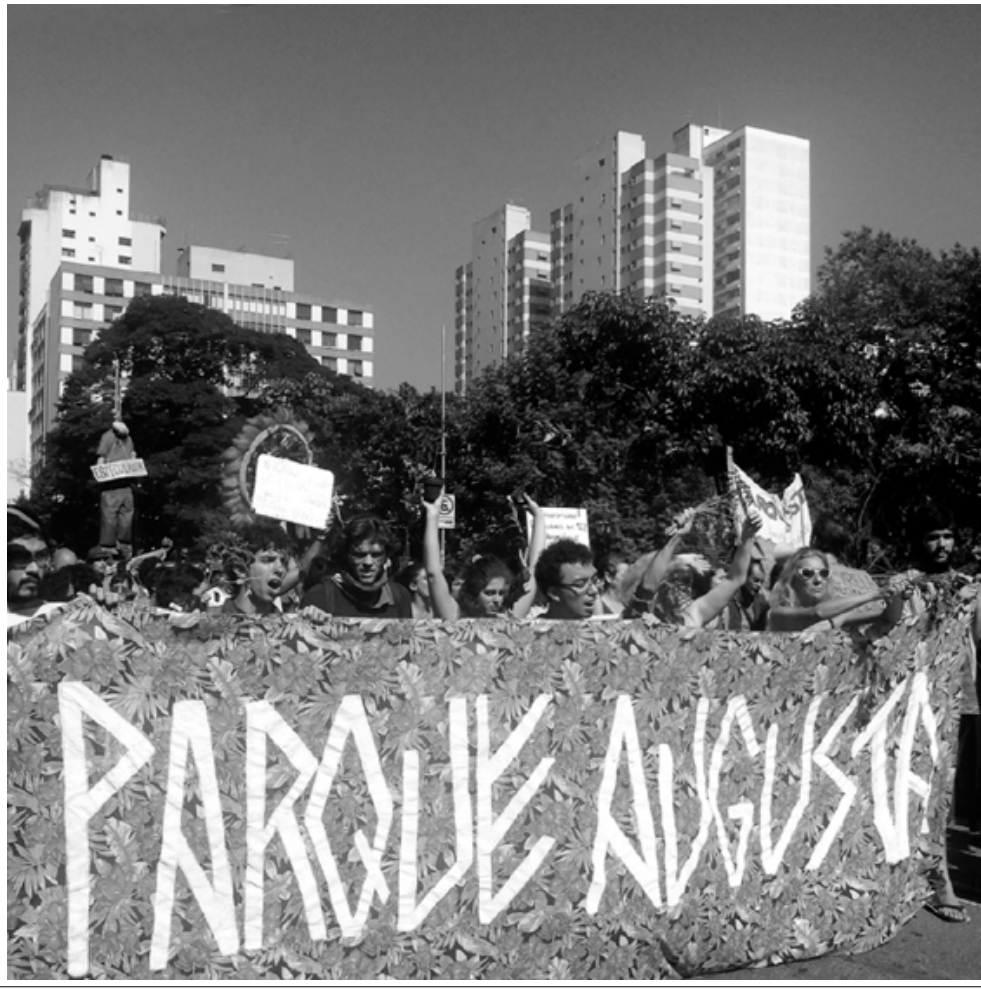

Fuente: Martins (2015).

el 2006 - fue un logro de las asociaciones de vecinos, Aliados do Parque Augusta y Samorcc, quienes lucharon por la creación del parque durante años. No obstante, siete años después de su creación, el proyecto se sancionó en el contexto de las manifestaciones del 2013 y las crecientes presiones del movimiento Organismo Parque Augusta. En el 2014, el Parque Augusta se ha legitimado en la revisión del Plan Director Estratégico, ${ }^{30}$ así que forma parte de la lista de todos los parques municipales existentes y propuestos para el municipio.

El 19 de mayo del 2015, durante la administración del alcalde Fernando Haddad, la primera audiencia pública de conciliación entre la municipalidad y los propietarios, celebrada por el Ministerio Público, propuso la adquisición de la tierra con recursos desviados por el ex alcalde Paulo Maluf, ${ }^{31}$ que regresaron a la municipalidad mediante bancos internacionales. En el 2016, la jueza Maria
${ }^{30}$ Ley Municipal de São Paulo 16.050 del 31 de julio del 2014.

${ }^{31}$ Afiliado al Partido Progresista, Paulo Maluffue alcalde de la ciudad de São Paulo en dos periodos: de 1969 a 1971 y de 1993 a 1996. 
${ }^{32}$ João Doria fue el alcalde de la ciudad de São Paulo por el Partido de la Social Democracia Brasileña, entre 2017 y 2018.

${ }^{33}$ Bruno Covas es el actual alcalde de la ciudad de São Paulo, por el Partido de la Social Democracia Brasileña.

${ }^{34}$ Decreto 58.289 del 26 de junio del 2018.

${ }^{35}$ Artículo 125 y 127 de la Ley Municipal de São Paulo 16.050 del 31 de julio del 2014.

\section{territorias 44}

Gabriella Pavlopoulos Spaolonzi sugiere que el terreno sea adquirido con títulos de potencial constructivo.

La siguiente administración municipal, del alcalde João Doria ${ }^{32}$ — entre el 2017 y el 2018-, propone establecer un acuerdo con los propietarios en forma de trueque: el terreno privado del Parque Augusta se cambiaría por un terreno público en el barrio de Pinheiros. La propuesta no recibe el apoyo del movimiento Organismo Parque Augusta, que ha considerado la creación del parque desde una escala ambiental municipal. Siendo un área de preservación, el terreno a la orilla del río Pinheiros también representa un interés colectivo. Sin embargo, de acuerdo con la óptica de los comunes urbanos, una buena solución local es adecuada siempre y cuando no exista conflicto de intereses en otra escala territorial (Harvey, 2014).

En mayo del 2017, a pedido de la municipalidad, los grupos pro Parque Augusta elaboraron un proyecto colectivo, cuyo programa restringe las construcciones permanentes a la pequeña sede administrativa y a los baños públicos; para los espacios libres prescriben la recolección de aguas lluvias, energía solar, vivero, huerta, arena para actividades educativas y preservación de los bosques. Empero, todavía no es posible evaluar si la implementación del parque adoptará las directrices del proyecto colectivo.

En el 2018, con la partida del alcalde João Doria y la posesión del vicealcalde Bruno Covas, ${ }^{33}$ comenzó un nuevo ciclo de discusiones. El instrumento de TPC es defendido por los activistas como la mejor solución para garantizar la preservación de la zona verde. El 26 de junio del 2018, el nuevo alcalde aprobó la legislación municipal $^{34}$ que regula el instrumento de TPC con donación amistosa o expropiación de la propiedad.

El 20 de septiembre del 2018, en la Justicia se aprobó el acuerdo para crear el Parque Augusta, por lo cual propietarios e inversionistas del terreno obtuvieron una Declaración de Potencial de Construcción Pasible de Transferencia. El cálculo es preparado con base en la ecuación de potencial constructivo, estipulada por el Plan Director Estratégico del 2014, ${ }^{35}$ que proporciona un factor de incentivo para la donación. Ampliamente utilizado en el caso de bienes declarados como patrimonios históricos, circunstancia en que el instrumento no involucra la donación de la propiedad. En el caso del Parque Augusta, al usar el factor de multiplicación para calcular el beneficio de la donación, hace que la magnitud de la bonificación garantizada a los propietarios del terreno sea incomprensible para la población. Souza et al. (2019, p. 10) demuestran que su aplicación en otras regiones de interés inmobiliario en la ciudad significa "una multiplicación equivalente a más de 62 veces el potencial original en Vila Mariana y casi 170 veces en Vila Prudente". Y, según el diario Folha de S. Paulo (Zylberkan, 2018), los interesados recibirán alrededor de 200 millones de reales en títulos con 
potencial de construcción, valor para la venta o aplicación en nuevos edificios. Además de la donación del terreno, el acuerdo prevé que las constructoras inviertan 10 millones en la implementación del Parque Augusta.

\section{El punto de vista de la iniciativa privada}

Ubicada en pleno centro de la ciudad y cortando la avenida Paulista, la calle Augusta es tradicionalmente identificada con la escena artística de São Paulo gracias a sus teatros. Se caracteriza por su intensa actividad comercial diurna y su fuerte tradición bohemia nocturna. Con la decadencia y la devaluación del centro de la ciudad desde la década de 1980, la región llegó a ser conocida por casas de prostitución y pequeños comercios. En los últimos 15 años, la región ha cambiado gradualmente con la contribución de nuevas inversiones: las 22 casas de prostitución existentes en el 2003 se redujeron a solo 6 en el 2013; los establecimientos comerciales durante el día se han ido modernizando y las propiedades antiguas se convirtieron en el objeto del interés inmobiliario (Pissardo, 2013).

Un ejemplo emblemático de este proceso es la reciente inauguración - en el 2016 - del nuevo Hotel Ca'D'Oro (figura 9), con dos torres de 32 pisos que en la esquina de las calles Augusta y Caio Prado, junto al parque Augusta, ocupa el terreno del hotel original, inaugurado en 1956 y demolido en el 2012. Más recientemente, la región se estableció por el aire bohemio nocturno, con jóvenes estudiantes de clase media y universitarios de toda la región metropolitana, que ocupan las calles y establecimientos diversos como bares, restaurantes, cafeterías y discotecas.

El área del Parque Augusta es objeto de interés de la iniciativa privada hace más de un siglo. En 1907, el terreno y la mansión de Flávio Mendonça y su esposa Evangelina Prado Uchôa fueron adquiridos por la Asociación de Instrucción de la Juventud Femenina. En 1968, después de décadas de funcionamiento, el Colegio des Oiseaux suspendió sus actividades y sus dependencias se convirtieron en propiedad de Teijin do Brasil hasta 1996. La compañía, que durante el periodo sufre varios cambios de nombre, presenta algunas propuestas para el terreno: hotel, supermercado y museo de música popular brasileña, que, por distintas razones, no fueron implementadas. A lo largo del tiempo, el terreno recibió distintos usos: de 1986 al 2013, se alquiló a una empresa de garajes y estacionamientos; de 1985 a 1987, fue ocupado por el Projeto SP con instalaciones temporales semejantes a un circo, que fue el escenario de varias bandas de rock de São Paulo.

En 1996, el área fue adquirida por la empresa Armando Conde Investimentos, del empresario Armando Conde. En el 2008, las constructoras Cyrela y Setin firmaron un compromiso para comprar el terreno y solicitaron la aprobación de la ciudad para un proyecto de uso mixto. Con territarias 44 231 
territarios 44
Figura 9. Nuevo Hotel Ca'D'Oro y obras para un nuevo residencial en la rua Augusta, número 75 (enfrente al Hotel)
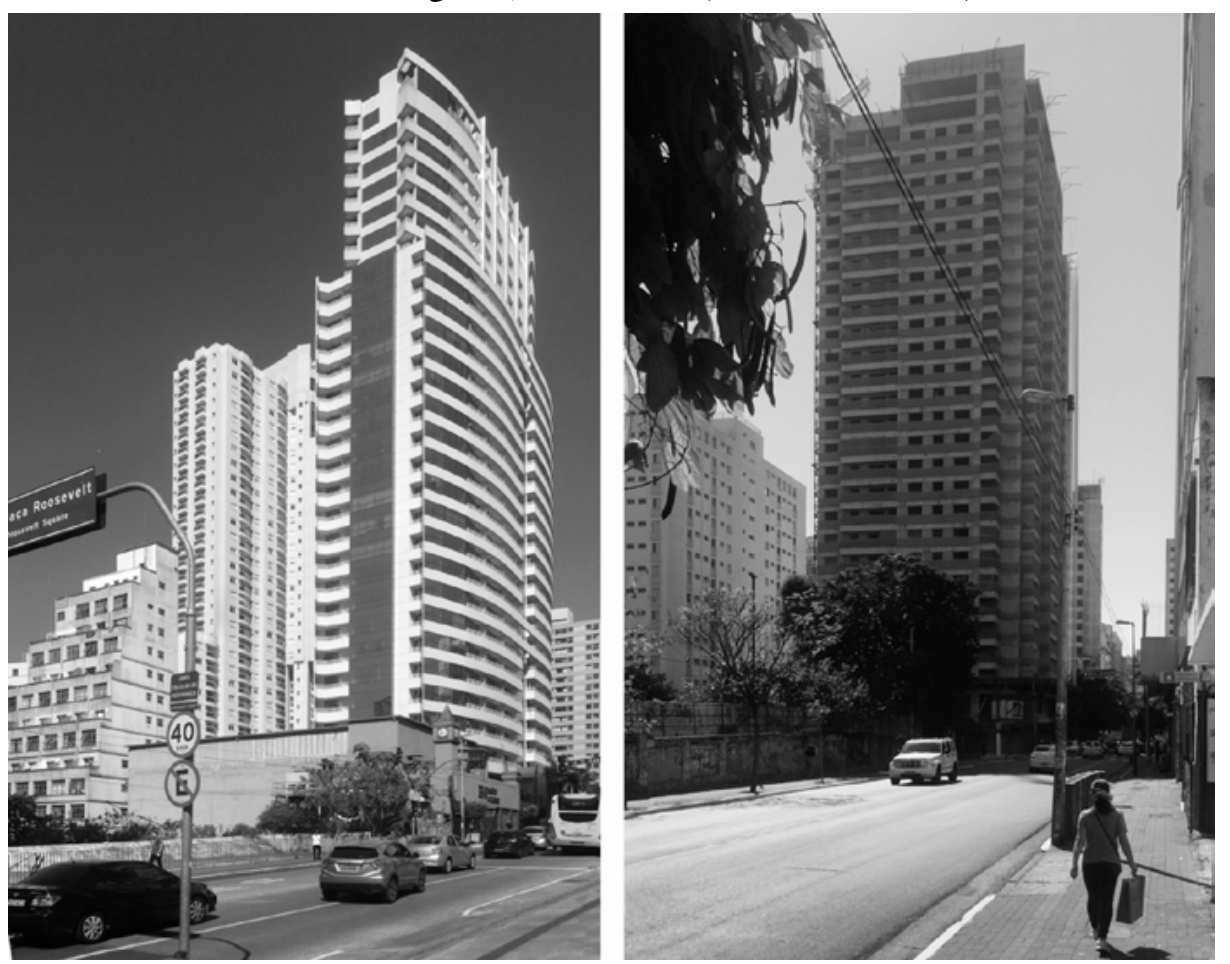

Fuente: Guerra (2019).

la firma del arquitecto y paisajista Benedito Abbud, el primer proyecto presentado por Setin y Cyrela se llamó "Nova Augusta”, mientras que el área verde pasó a llamarse Parque Caio Prado. El proyecto prevé la construcción de dos torres y la conversión del área restante en un parque, con acceso público, administración privada, gerenciamiento de árboles y restauración de los edificios históricos. La propuesta prevé una "franja de amortiguación" de 10 metros para separar la construcción del bosque, la creación de un bulevar en la calle Gravataí, formando un eje de conexión del proyecto inmobiliario con la Plaza Roosevelt y mejoras en una escuela pública local.

En el 2012, junto a Abbud, el empresario Antonio Setin presentó el proyecto en una audiencia pública con una clara perspectiva de transformación del entorno (Prefeitura Municipal de São Paulo, 2012). El vencimiento del DUP y la posible aprobación del proyecto tuvieron un impacto 
Figura 10. Puerta cerrada del terreno en disputa, situación actual a 5 de mayo del 2020

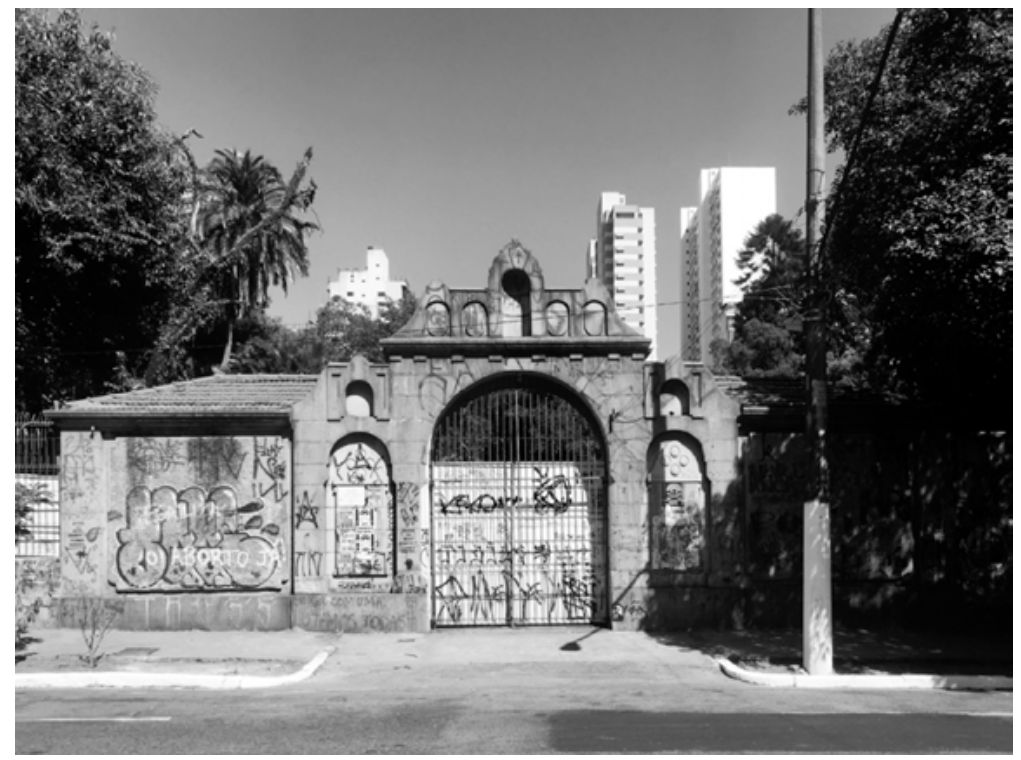

Fuente: Guerra (2019).

negativo en las manifestaciones del 2013. En una entrevista a la Folba de S. Paulo, el 15 de agosto del 2013, Armando Conde presentó el segundo proyecto, con torres de 110 metros de altura, que infringen la medida determinada por la Resolución de Patrimonio Histórico, por lo que se requiere la revisión de la propuesta (Rosati, 2013). En el 2014, las constructoras presentaron un tercer proyecto para aprobación: tres edificios de hasta 45 metros, que ocupan el $40 \%$ del terreno, con el resto destinado a un parque abierto al público, pero con administración privada. Como se mencionó, el proceso de aprobación municipal del proyecto fue suspendido por una acción judicial.

\section{Consideraciones finales}

El activismo de acción directa en la creación del Parque Augusta revela nuevas formas de ver y usar el espacio urbano, consolidando - a principios del siglo XXI- un tipo espontáneo de apropiación y transformación colectiva de São Paulo. Un fenómeno que llamamos de "ciudad en fiesta, ciudad en disputa": las nuevas modalidades de colaboración a escala local están equipadas con tácticas efímeras que buscan la resignificación del espacio urbano y de la vida cotidiana, fortalecen el sentido de la comunidad, fomentan el debate político en las relaciones cotidianas y aumentan la diversidad de las expresiones 
culturales en un territorio de pequeña escala. En ese proceso de lucha por el derecho a la ciudad, diferentes grupos enfrentan la cuestión de proponer usos para un terreno bien ubicado y subutilizado. Las escenas futuras del terreno implican alternativas de espacios públicos, privados o mixtos que permitan desarrollar una reflexión crítica, considerando las tácticas de resistencia urbana y su relación conflictiva con el poder público y la actividad económica. La investigación permite presentar la evolución histórica, entrelazando conceptos sobre el espacio público y el bien común con la dinámica de la urbanización.

A lo largo del texto, se trataron dos aspectos articulados presentes en el caso del Parque Augusta. El primero considera la existencia de una tensión entre la libertad de acción y el reconocimiento institucional, comprobado al verificar - con el tiempo y en el espacio analizado- que los movimientos involucrados dejaron de usar tácticas de acción directa, adoptando estrategias de acción de formato más institucionalizado y jerárquico. Para llegar a ciertas soluciones, la gestión puramente horizontal muchas veces no alcanza la rapidez de respuesta en el proceso de toma de decisiones (Harvey, 2014). El segundo aspecto señala la pérdida de importancia del activismo, restringido en su protagonismo por demandas judiciales alrededor del 2015. En ambos casos, debido a la precariedad de los canales públicos oficiales para la participación social, la disputa se desplazó de la escena urbana - el terreno del parque y el área circundante- a la escena política y judicial. Como una suerte de cercamiento (Dardot \& Laval, 2017; Bollier, 2016; Harvey, 2014), la judicialización de la lucha inhibió e incluso imposibilitó el uso espontáneo del espacio.

Basada inicialmente en el ejercicio constante de la ciudadanía alternativa, la disputa por el Parque Augusta revela el largo camino por recorrer que le queda a la lucha por el bien común para lograr resultados efectivos. La idea de una ciudad apropiada por acciones colectivas no es inmune a la cooptación por las prácticas neoliberales, desmantelando la propia lógica de producción de lo común (Dardot \& Laval, 2017). En su etapa actual de desarrollo, en la cual todavía no existe un consenso social sobre el significado y el alcance del bien común, los esfuerzos por el derecho colectivo para dar forma a la ciudad dependen de la regulación estatal (Harvey, 2014, 2012).

La posibilidad de reunirse y simplemente actuar en común es uno de los principales problemas que surgen en el siglo XXI. Sin embargo, el acoso del mercado inmobiliario y de los intereses del capital sobre el control democrático de los usos del espacio público tiene como respuesta exclusiva la mediación del poder estatal. La práctica voluntarista de grupos comunitarios, defendida por varios autores presentados en la sección dedicada a la conceptualización teórica, todavía está huérfana de mecanismos sociales 
que garanticen sus logros dentro de la propia sociedad. Según el presente informe del episodio Parque Augusta, en algún momento del proceso, los activismos son integrados a la disputa oficial institucional, sea en el ámbito municipal o en el ámbito judicial. Con el tiempo, la acción directa en esos territorios se vuelve inviable y el logro concreto - es decir, la creación de un nuevo parque - solo puede ocurrir dentro de un marco regulatorio oficial.

En la actual coyuntura de sumisión de las políticas públicas a los intereses económicos, el compromiso ciudadano para reanudar la vida pública está envuelto en acentuadas contradicciones. Como un proceso histórico contemporáneo, en progreso, las diferentes proposiciones teóricas presentadas en contextos distintos aún no han podido llegar a un diagnóstico preciso. Los reclamos colectivos dirigidos a la creación y protección de los comunes urbanos, marcados por apropiaciones constantes y una gestión colaborativa, paradójicamente pueden impulsar los mecanismos de gentrificación, como en el ejemplo analizado en este artículo. En el Parque Augusta, la experiencia de una propiedad colectiva promovida por movimientos artísticos se desarrolla en acciones judiciales, luego por decisiones administrativas de política pública y, finalmente, por la llegada masiva de nuevos proyectos inmobiliarios privados dirigidos a la clase media, tanto residencial como cultural. El proceso es similar en muchas ciudades del mundo, cuando se crean parques y espacios públicos atractivos (Hardt \& Negri, 2016; Zukin, 2009).

El terreno ha estado cerrado por más de cuatro años y, durante este periodo, los aspectos negativos se hacen cada vez más evidentes: la pérdida del carácter público del espacio, una vez que la población está prohibida para usarlo; el proceso de degradación del área, debido a la falta de uso y mantenimiento; la dilatación del proceso legal, en el cual las decisiones del Ministerio Público y de la Justicia pueden extenderse indeterminadamente en cuanto a su contenido y temporalidad (figura 10).

Mientras tanto, con las puertas cerradas, la disputa por el Parque Augusta es todavía un proceso abierto.

\section{Referencias}

Bartalini, V. (1996). Os parques públicos municipais em São Paulo. Paisagem e Ambiente, (9), 125-148. https:// doi.org/10.11606/issn.2359-5361. v0i9pl25-148

Bauman, Z., \& Mauro E. (2016). Babel: entre a incerteza e a esperança. Zahar.

Bollier, D. (2016). Pensar desde los comunes: una breve introducción. Traficantes de sueños.

Caldeira, T. P do Rio. (2000). Cidade de muros: crime, segregação e cidadania em São Paulo. Editora 34.

Caldeira, T. P do Rio. (2012). Inscrição e circulação: novas visibilidades e configurações do espaço público em São Paulo. Novos Estudos Cebrap, (94), 
31-67. https://doi.org/10.1590/ S0101-33002012000300002

Carvalho, L. K., Maziviero, M., \& Imbronito, M. (2019, 20 de diciembre). Resistências no espaço urbano: um olhar sobre a perspectiva histórica das experiências coletivas e a articulação de novos ativismos. Vitruvius, Arquitextos. https://www.vitruvius.com.br/revistas/read/arquitextos/20.235/7587

Castells, M. (1979). La cuestión urbana. Siglo XXI Editores.

Castells, M. (2017). Redes de indignação e esperança: movimentos sociais na era da internet. Editora Zahar.

Castro-Coma, M., \& Martí-Costa, M. (2015). Comunes urbanos: de la gestión colectiva al derecho a la ciudad. EURE: Revista Latinoamericana de Estudios Urbano Regionales, 40(125), 131-153. https://doi.org/10.4067/ S0250-71612016000100006

Dardot, P., \& Laval, C. (2017). Comum: ensaio sobre a revolução no século XXI. Boitempo Editorial.

Di Felice, M. (2012). Netativismo: novos aspectos da opinião pública em contextos digitais. Revista FAMECOS: midia, cultura e tecnologia, (19), 27-45. https://doi.org/10.15448/19803729.2012.1.11339

Diamond, L. (2015). In search of democracy. Routledge.

Foucault, M. (1979). Microfísica do poder. Edições Graal.

Habermas, J. (1984). Mudança estrutural da esfera pública. Investigações sobre uma categoría da sociedade burguesa. Editorial Tempo Brasileiro.

Hardt, M., \& Negri, A. (2016). Bem-estar comum. Record.

Harvey, D. (2012). O direito à cidade. Lutas Sociais, (29), 73-89. https://revistas. pucsp.br/ls/article/view/18497

Harvey, D. (2014). Cidades rebeldes: do direito à cidade à revolução urbana. Boitempo Editorial.

Hori, P. (2018). Práticas urbanas transformadoras: o ativismo urbano na disputa por espaços públicos na cidade de São Paulo (tesis de Maestría). Facultad de Arquitectura y Urbanismo, Universidad de São Paulo.

Kliass, R. (1993). Parques urbanos de São Paulo e sua evolução na cidade. Pini Editora.

Lefebvre, H. (1968). Le droit à la ville. Èdtions Anthropos.

Lefebvre, H. (2001). O direito à cidade. Centauro.

Limnios, G., \& Furlan, S. (2013). Parques urbanos no Município de São Paulo-SP (Brasil): espacialização e demanda social. Revista Labverde, (6), 173-189. https://doi.org/10.11606/ issn.2179-2275.v0i6pl73-189

Macarrão, L. (2009). O parque público na cidade de São Paulo: 1989-2008 (tesis de Maestría). Facultad de Arquitectura y Urbanismo, Universida Federal de Bahia.

Marino, C. (2018). Cidade em festa, cidade em disputa: ativismo e apropriação do espaço urbano em São Paulo no início

Cintia Marino, Abilio Guerra 
do século XXI (tesis de Doctorado). Facultad de Arquitectura y Urbanismo, Universidad Presbiteriana Mackenzie. Marino, C. (2019). Ativismo e apropriação do espaço urbano em São Paulo. Arq. urb, (23), 170-184. https://revistaarqurb.com.br/arqurb/article/view/46

Maziviero, M. C., \& de Almeida, E. (2017). Urbanismo Insurgente: ações recentes de coletivos urbanos ressignificando o espaço público na cidade de São Paulo. Anais do XVII Encontro Nacional da Associação Nacional de Pós-Graduação e Pesquisa em Planejamento Urbano e Regional, 17(1). https://anpur.org.br/ xviienanpur/principal/publicacoes/ XVII.ENANPUR_Anais/ST_Sessoes_Tematicas/ST\%206/ST\%206.1/ ST\%206.1-04.pdf.

Mello-Théry, N. (2011). Conservação de áreas naturais em São Paulo. Estudos avançados, 25(71), 175-188. https://doi.org/10.1590/S010340142011000100012

Organismo Parque Augusta (2014, mayo). Revista Organismo Parque Augusta, 01. https://issuu.com/organismopa/ docs/revistaopa.0.1

Ostrom, E. (1990). Governing the Commons. Cambridge University Press.

Paquot, T. (2010). L'espace public. La Découverte.

Paulista, A., Peretto, F., \& Seo, H. (2019). O Parque Augusta e o milagre da multiplicação do potencial construtivo: o caso das doações de imóveis para implantação de Parques Municipais no
PDE-SP de 2014 (ponencia). Anais do XVIII Enanpur.

Piketty, T. (2014). O capital no século XXI. Editora Intrínseca.

Pissardo, F. (2013). A rua apropriada: um estudo sobre as transformações e usos urbanos na Rua Augusta (São Paulo, 1891-2012) (tesis de Maestría). Facultad de Arquitectura y Urbanismo, Universidad de São Paulo.

Prefeitura Municipal de São Paulo (2012). Transcrição da apresentação e proposta para utilização imobiliária e implantação de área verde, no terreno localizado entre as Ruas Caio Prado, Augusta e Marquês de Paranaguá. Audiência Pública realizada no Hotel Excelsior em 22 de março de 2012. Secretaria Municipal do Verde e do Meio Ambiente (svma); Conselho Municipal do Meio Ambiente e Desenvolvimento Sustentável (CADES). https://www.prefeitura.sp.gov.br/cidade/secretarias/ upload/chamadas/ata_3_apresent_ pub_caioprado_1334324448.pdf

Rancière, J. (2010). A estética como política. Devires-cinema e humanidades, 7(2), 14-36. https://www.saavedrafajardo.org/Archivos/respublica/ numeros $/ 26 / 00 . p d f$

Rolnik, R. (2015). Guerra dos lugares a colonização da terra e da moradia na era das finanças. Boitempo Editorial.

Rosati, C. (2013, 13 de agosto). Verde ou vertical: pode estar próximo o desfecho de disputa por terreno em que o dono pretende erguer prédios e que vizinhos querem 
transformar em parque. Folha de $S$. Paulo, Caderno Cotidiano. https:// wwwl.folha.uol.com.br/paywall/signup.shtml?https://wwwl.folha.uol. com.br/fsp/cotidiano/124057-verdeou-vertical.shtml

Samorcc. (2016, 11 de octubre). Carta ao Prefeito João Dória: proposta de atuação na avenida Paulista. Samorcc. www. samorcc.org.br

Sandler, D. (2020). Grassroots urbanism in contemporary São Paulo. Urban Design International, 25(1), 77-91. https://doi.org/10.1057/s41289020-00108-8

Santos, B. D. (2015). Revueltas de indignación y otras conversas. Alice.

Sassen, S. (2014). Expulsions: Brutality and Complexity in the Global Economy. Belknap Press.
Setin, A. (2015, 6 de marzo). Parque Augusta vai ter segurança e wifi, diz presidente da Setin. Carta Capital. https://www.cartacapital.com.br/ sociedade/201cparque-augusta-vaiter-seguranca-e-wifi20ld-diz-presidente-da-construtora-setin-4146/

Žižek, S. (2012). O ano em que sonbamos perigosamente. Boitempo Editorial.

Zukin, S. (2009). Naked city: The death and life of authentic urban places. Oxford University Press.

Zylberkan, M. (2018, 22 de noviembre). Empreiteiras podem lucrar até R\$ 95 milhões com acordo do parque Augusta”. Folha de São Paulo. https:// bit.ly/2QvSPCc 